\title{
The Interaction Effect of Complimentary Assets on Relationship between Information and Communication Technology and Public Health Outcomes
}

\author{
Supunmali Ahangama and Danny Chiang Choon Poo \\ Department of Information Systems, School of Computing, National University of Singapore, \\ 13 Computing Drive, Singapore 117417 \\ supunmali@comp.nus.edu.sg, dannypoo@nus.edu.sg
}

\begin{abstract}
This cross-national study evaluates the contingency of the relationship between ICT initiatives and public health outcomes on (1) education; (2) macro-economic stability and; (3) institutions. Resource Based View's resource complementary perspective and literature on Information and Communication Technology and delivery of public health are used as the guiding theoretical framework. Publicly accessible archived data from more than 150 nations are collected to comprehend the interaction effect. Delivery of public health outcomes is measured through mortality rate (adult), availability of sanitation facilities, incidence of TB and under nourishment. The results indicated that ICT initiatives interact with above three contingencies affecting public health outcomes. Education level positively moderated the relationship between ICT and public health outcomes. Institutions moderated the relationship of ICT and public health outcomes in a positive direction. The moderating effect is measured using PLS. Implications of the findings for theoretical discourse of the resource complimentary perspective and future research are discussed.
\end{abstract}

Keywords: public health, Information and communication technology (ICT), resource complementary perspective, country level, PLS.

\section{Introduction}

According to the definition of the World Health Organization (WHO), public health is "all organized measures to prevent disease, promote health, and prolong life among the population as a whole". Rather than concentrating on eradication of a single disease, public health focuses on the entire system, without limiting to individual patients or diseases. Improved public health outcomes and prevention of diseases can be achieved in low resource environments by investing in information and communication technology (ICT) tools. ICT applications would permit timely data collection, processing, storage and dissemination of health information to appropriate parties. Thus, public health policy makers and healthcare officials must invest in accessible, affordable applications focusing on entire community. ICT tools like health information systems, surveillance systems, m-health, and telemedicine could be used to monitor health concerns of the 
population and promote healthy practices and behaviors. Moreover, the internet facilitates unparalleled access to important health information and it has become a common practice among patients and public (Heilman et al. 2011). For example, Wikipedia can be considered as a key tool for promoting public health and according to Pew Internet 2009 survey on health information, 53\% of e-patients had used it (Jones and Fox 2009).

Introduction of ICT tools to healthcare services is extremely challenging due to numerous factors varying from limited availability of financial support to lack of proper framework for public health delivery. As per the World Bank, financial and other resource spending can be justified as improvement in public health leads to economic growth by reducing production losses caused by sick workers, by saving resources that would have been used for treating patients etc. (World Bank 1993). Thus, as supported by literature related to public health, it can be argued that a better public health system will lead to economic growth and poverty alleviation.

Most research has focused on demonstrating the contribution of ICT on improving healthcare services such as quality improvements and cost reductions (Jha et al. 2009; Khoumbati et al. 2006; Wu et al. 2006). Moreover, many studies have been restricted to evaluating the effectiveness of ICT solely for clinical services rather than on entire community (Jha et al. 2009; Wu et al. 2006) where, their main focus had been at micro level (specific healthcare organizations, regions or countries) and on specific aspects (e.g. clinical or personal) in implementation. As highlighted by Raghupathi and $\mathrm{Wu}$ (Raghupathi and Wu 2011), most of such research work are case studies of a specific country (Braa et al. 2007; Byrne and Sahay 2007; Jennett et al. 2004; Tomasi et al. 2004) or of a set of countries (Tomasi et al. 2004) or conceptual studies (Connell and Young 2007). Due to small sample sizes and failure of providing a complete cross-country level view, it is hard to generalize and apply such findings at different country levels. There is a dearth of country level studies carried out relevant to the contribution of ICT factors on better public health outcomes. Even in the limited cross-country research carried out, the moderating effect on the relationship of ICT on delivery of public health has not been considered. Thus, performing a cross-country level quantitative empirical study to assess the interaction effect on relationship between ICT factors and public health outcomes can be considered as a key research gap to be answered.

Using the resource complementarily perspective of Teece (Teece 1986), we propose that the relationship between ICT and public health outcomes is moderated by national environmental factors, namely, (1) education level; (2) macro-economic stability and; (3) institutional. These three factors will represent the political, economical and social factors of a nation. Delivery of public health outcomes are considered based on (1) mortality rate (adult); (2) availability of sanitation facilities; (3) incidence of TB and; (4) under nourishment. These complementary assets will be modeled using secondary data of 157 countries.

RQ: How do a nation's complementary assets (education level, macro-economic stability and institutions) interact with national ICT initiatives in predicting its public health outcomes?

The rest of the paper is organized as follows. First, the Theoretical Framework is briefly explained with role of ICT on public health delivery. Second, Descriptions on 
Hypothesis Development and Research Design are dealt with. Third, we discuss the results and implication and finally, limitations and conclusions are discussed.

\subsection{Theoretical Framework}

According to WHO, two key roles of ICT on public health outcome are (1) organizing and distribution of health information to healthcare professionals and public and; (2) educating public on preventive measures. Various forms of ICT tools could be used in collection, analysis and communication of healthcare information. e-Health can be recognized as an essential tool in ensuring a safer, efficient and sustainable healthcare delivery around the world via wireless communication systems using computers and mobile phones. WHO program on e-health for healthcare delivery could be considered as an e-Health initiative where tele-consultations and tele-referrals are used to connect healthcare centres in remote areas (Raghupathi and $\mathrm{Wu}$ 2011). m-Health refers to the use of smart phones and other hand held computers for health care delivery and it encourages constantly to seek new health information from various media content and by participatory collaboration (Ahangama et al. 2014). Mobile applications allow tele-consultations between doctor and patient, wellness management, short message service (SMS) for behaviour change (Cole-Lewis and Kershaw 2010; Fjeldsoe et al. 2009). In addition, location based services enable community data collection and epidemiology and public health surveillance (Aanensen et al. 2009). Geographical Information Systems (GIS) allow mapping individual data using location reference data and it provides the opportunity to analyse the risk of disease spread, analyse environment hazards, carry out vaccination campaigns and locate healthcare services. . Even though, these technologies facilitate improvement in public health in general, the level of influence varies from nation to nation. The level of influence of these technologies on public health depends on other macro level factors in different countries.

Teece's (Teece 1986) concept of complementary assets describes that for commercializing a new product profitably, a firm needs access to complementary assets (manufacturing and distribution facilities) in a favourable manner (Teece 2006). Complementary assets are resources or capabilities used by firms to capture the profits associated with a strategy, technology or innovation (Shaw 1998). Competitor will not be able to gain a competitive advantage even if they copied and launched the same product as they do not have access to complementary assets possessed by the original producer. Complementary assets can be categorized into two different areas as resource co-presence view and resource channelling view based on the Resource Based View (RBV) (Barney et al. 2001). Resource co-presence view (interaction perspective) describes that a resource can be a complementary asset if its presence increases the value or outcome of another resource. Resource channelling view describes that complementary assets are formed when resource s are used in reciprocally reinforcing manner (Ravichandran and Lertwongsatien 2005). Even though, this was initially introduced to apply to organisational level, many studies have applied complementary asset perspective on country level too (Ahangama and Poo 2012; Krishnan and Teo 2011). Thus, former can be applied into our study to understand why certain nations 
have better public health outcomes compared to other nations (Mithas et al. 2009). Complementary assets will be helpful in achieving high delivery in public health outcomes from health care related ICT innovations. Rather than developing and deploying ICT tools itself, it is important to understand the complementary assets that could provide better utility. Moderating variables (macro-economic stability, education and institutions (Kauffman and Kumar 2008; Porter and Schwab 2009)) used in this study will be complementary assets that will enhance the relationship between ICT factors and public health outcomes.

\section{Hypothesis Development}

Through many prior studies it had been identified that ICT influences the delivery of public health (Jha et al. 2009; Khoumbati et al. 2006; Wu et al. 2006). The dearth of published literature on quantitative empirical research, studying the influence of national environmental factors (moderating variables) on ICT initiatives and delivery of public health outcomes in a country, persuaded us to develop our study aiming to fill that research gap. The research model (Fig. 1) was developed based on prior literature and theoretical frameworks mentioned above (section 1.1) and they will be tested using country level archived data.

\subsection{Moderating Effect of Education Level}

When the public become more educated they tend to care more about their own health and health of their family members and will follow health risk preventive practices. A high level of public health can be achieved with better educated and trained citizens (Ackerson and Viswanath 2009). Education level and knowledge of public is important for proper usage of healthcare applications for retrieval of trustworthy healthcare information, to communicate and to apply them correctly and in a timely fashion. When public is educated and computer literate, they tend to identify the use of web based and mobile based healthcare systems and they will continue to use such systems in an advanced manner (e.g. group support systems, online discussion forums, echannelling) to manage their health and protect themselves from diseases while providing feedback to improve systems (Bagchi et al. 2005; Wu et al. 2006).

We recognize that the countries with educated community are in a better position to carry out and utilize ICT initiatives leading to low mortality rates (adult), high availability of sanitation facilities, low incidence of TB and low under nourishment. For example, highly educated community will use mobile applications to manage diseases like diabetes and they will look for new technology. We can hypothesize that when there is better education level among the community, higher benefits of ICT can be achieved to increase the public health outcomes.

H1: The relationship between ICT factors in a country and its public health outcome is moderated by education level. The relationship becomes stronger when education level is high and becomes weaker when education level is low. 


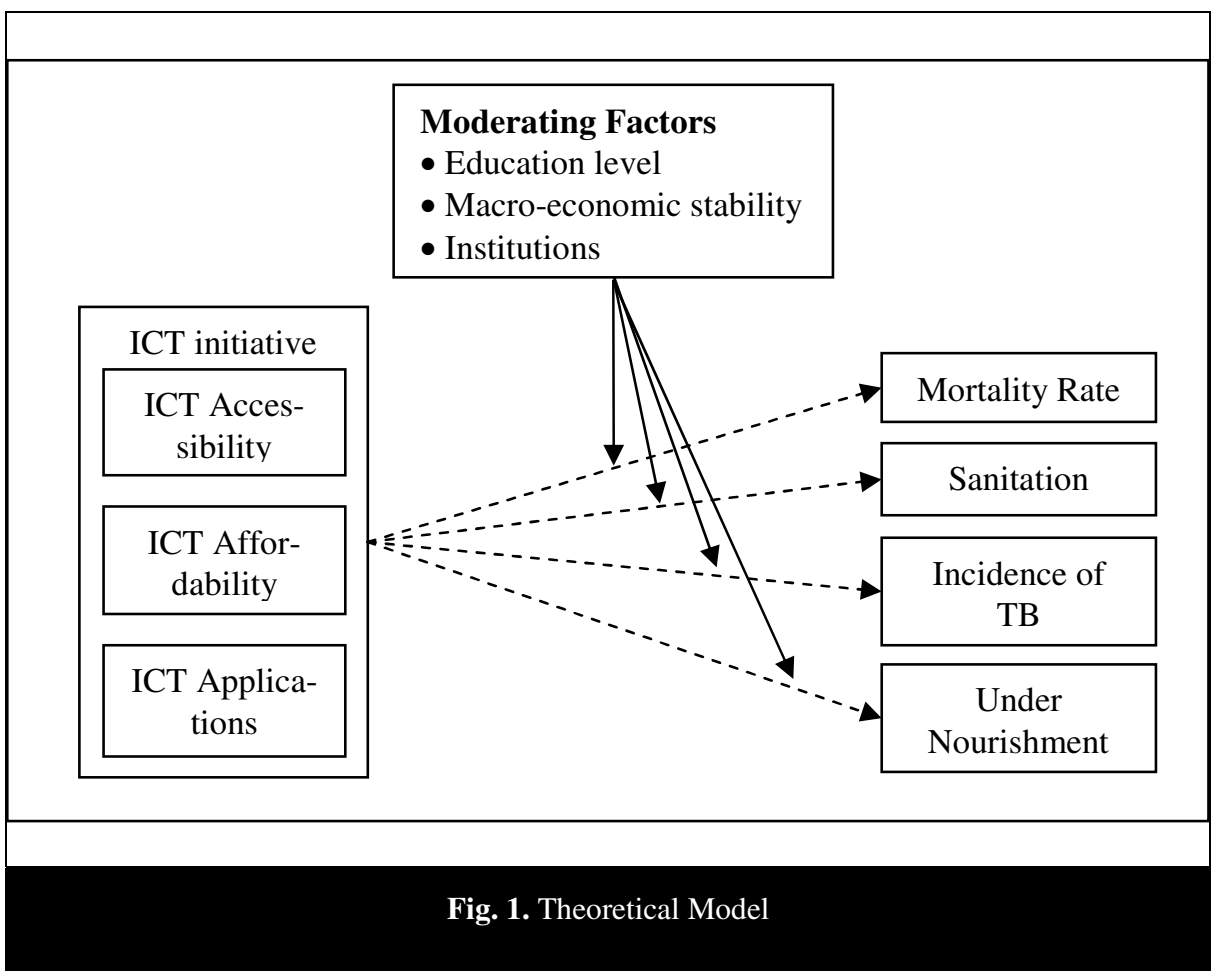

\subsection{Moderating Effect of Macro-economic Stability}

A low inflation rate with declining budget deficits and trade deficits leads to the maintenance of macro-economic stability of a country. Stability of the macro-economic environment plays a central role in carrying out ICT initiatives in a country. With stable macro-economic conditions advanced countries in the world are more likely to carry out e-government development (Srivastava and Teo 2007), for healthcare too. When the macro-economy of a country is unstable, they may not be able to invest in ICT applications for healthcare. High inflation may lead governments to provide the people with only the essential services in the health sector rather than providing services like preventive care or healthcare education.

Relationship between ICT enabled applications and public health outcomes may be higher in countries with better macro-economic stability compared to unstable countries. We recognize that the wealthy countries are in a better position to carry out ICT initiatives leading to low mortality rates (adult), high availability of sanitation facilities, low incidence of TB and low under nourishment. For example, with better macro-economy, a nation is able to provide safer water and sanitation facilities to its community. Thus, following hypothesis was established in identifying the major role played by macro-economic stability of a country in developing and in implementing ICT relevant to healthcare. 
H2: The relationship between ICT factors in a country and its public health outcome is moderated by macro-economic stability. The relationship becomes stronger when the stability of macro economy is high and becomes weaker when macro-economic stability is low.

\subsection{Moderating Effect of Institutions}

Institutional environment (both public and private) shapes up the framework within which individuals, firms, and governments interact to generate income and wealth in the economy (WEF- global competitive index (Porter and Schwab 2009)). While focusing on the legal framework, it also considers on how societies share the benefits and accept the burden of development strategies. Various political and policy modifications are required to amalgamate ICT tools to daily operations of public healthcare industry smoothly. There should be a suitable framework to assist secure and hassle free dissemination of information between various stakeholders across geographical boundaries.

With better institution framework, a nation will be in a better position to carry out ICT initiatives leading to low mortality rates (adult), high availability of sanitation facilities, low incidence of TB and low under nourishment. For example, proper framework to handle annual vaccination programs will be useful in reducing the incidence of infections and improving the immunization. We can hypothesize, that when there is better structure of institution, higher benefits of ICT can be achieved to increase the public health outcomes.

H3: The relationship between ICT factors in a country and its public health outcome is moderated by institutions. The relationship becomes stronger when the quality of institutions is high and becomes weaker when quality of institutions is low.

\subsection{Control Variables}

Three control variables that could explain the variance of predictor ICT are considered. We controlled physician (both generalists and specialists) density and nurse and midwife personnel density (proxy for quality of healthcare service) obtained for 2010 from World Development Indicator (WDI) Database at the World Bank website. It is the amount of health workforce per 10, 000 population (Mithas et al. 2009). Then we controlled the number of hospital beds per 10,000 of the population as it is an indicator of quality of healthcare infrastructure of a country (Mithas et al. 2009). The number of hospital beds for 2010 is obtained from WDI database and are composed of beds available in public, private, general and specialized hospitals.

\section{$3 \quad$ Research Design}

For hypothesis testing, a cross sectional analysis of 157 countries is used. 2011 is used as the base year for dependent variable and values for all the other constructs are 
captured in previous years. Secondary data had to be used as it is not feasible to collect primary data within the time and resource constraints and also because secondary data will allow easy reproducibility and make the design generalizable (Kiecolt and Nathan 1985). Additionally, as the data is gathered from different sources, the common method bias could also be avoided (Woszczynski and Whitman 2004). The main data sources are (1) World Bank ICT at-a-glance country database 2008 (World Health Organization 2011), (2) WDI database 2011, (3) WEF Global competitiveness report 2008-2009 and (4) UNDP Human Development Report 2013 (Porter and Schwab 2009). These reports are considered to be reliable sources and many authors have used these data in their research. For example, WDI database is used by Raghupathi and Wu (Raghupathi and Wu 2011; Wu and Raghupathi 2012) to study the impact of four ICT factors on delivery of public health. These organizations follow rigorous procedures to maintain the reliability and validity of these data. To ensure quality of these data, for example, (1) data is collected only from CEOs or equivalent high ranked officials, (2) respondents can answer in their preferred language, (3) administration of survey in several modes (face-to-face, telephone and online interviews or surveys) and (4) performs a careful editing of data before aggregating to get country level data (Porter and Schwab 2009).

\subsection{Operationalization of Constructs}

We used four indicators of public health as dependent variables, namely, mortality rate (MR), sanitation, TB infection and under nourishment. Many prior studies (Mithas et al. 2009; Ngwenyama et al. 2006) had used life expectancy rate (LER) or MR to measure the quality of healthcare systems. However, the use of LER or MR will not be adequate to measure the quality of a public health system as it only considers the length of life (Robine et al. 1999). Thus, in this study we consider 4 indicators to represent different aspects of health to reveal the quality and performance of public health (OECD 2013). MR (adult) is measured using average of MR between ages 15 and 60 per 1,000 female adults and per 1,000 male adults. Average of improved sanitation facilities (\% of population with access) and improved water source (\% of population with access) are used to measure sanitation facility. Incidence of tuberculosis per 100,000 people is used as the indicator for TB infection. Degree of under nourishment will be indicated as the $\%$ of population getting incomplete or unbalanced nourishment. These dependent variables are obtained from WDI database for year 2011.

The high order construct for ICT is developed using (1) accessibility for ICT services, (2) affordability of ICT services and (3) adoption of ICT services in government and business. The data are obtained from World Bank ICT at-a-glance country database 2008 and average of these scores are used as the ICT index. Accessibility is composed of (1) telephone mainlines per 1,000 people; (2) international voice traffic minutes per person; (3) mobile phone subscriptions per 1,000 people, percentage of population covered by mobile telephony; (4) internet users per 1,000 people; (5) personal computers per 1,000 people; and (6) percentage of households with television. Affordability is composed of (1) price basket for residential fixed line (US\$ per month); 
(2) price basket for mobile (US\$ per month); (3) price basket for internet (US\$ per month) and (4) telephone average cost of call to US (US\$ per three minutes). ICT applications are measured using (1) ICT expenditure (\% of GDP); (2) secure internet servers per 1 million people; (3) percentage of schools connected to the internet and (4) egovernment readiness index (scale $0-1$ ).

Education index for 2010 obtained from UNDP Human Development Report 2013 is measured using (1) mean of years of schooling for adults aged 25 years and (2) expected years of schooling for children of school entering age. Macro-economic stability index is taken from WEF Global competitiveness report 2008-2009 (Porter and Schwab 2009). This is composed of (1) government surplus/ deficit, (2) national savings rate, (3) inflation, (4) interest rate spread and (5) government debt. Institutions index is obtained from the same report mentioned above and it is developed using (1) intellectual property rights, (2) ethics and corruption, (3) undue influence, (4) government inefficiency and (5) security. These three indices had been used in past studies to understand the e-government development (Srivastava and Teo 2007).

\section{$4 \quad$ Analysis and Results}

The model is represented with hierarchical constructs (high order construct) to allow theoretical parsimony and to reduce the complexity of the model. The dimensions for ICT were measured using formative constructs, such as accessibility and affordability and adoption of ICT is represented as first order constructs. Moreover, MR, sanitation, TB infection and under nourishment are formatively related to public health construct (second order construct). To treat missing data, we used 'mean value replacement' option as it is the recommended approach in PLS.

\subsection{Hypothesis Testing}

We used partial least squares (PLS) to test the interaction effects. PLS is appropriate when handling formative constructs and when testing theories in the initial stages of development (Keil et al. 2000). In this study to detect the interaction effect, we employed the product of sum (PS) approach of Goodhue et al. (Goodhue et al. 2007) instead of using product indicator approach of Chin et al. (Chin et al. 2003) as it provides less statistical power. Moreover, it is not possible to use the latter when the predictor variables are formative. Thus, we used two-stage approach, where in stage 1, the main-effect PLS path model is executed to get latent variable scores. In stage 2, the interaction term is computed as a product of latent score of the predictor and the moderator. The interaction term and the latent variable score of predictor and moderator could be used as independent variables in a multiple linear regression on public health construct (on latent score of it) (Henseler and Fassott 2010) or it could be implemented within the PLS. We implemented a PLS model using new interaction terms. Furthermore, it is important that all the interaction terms are entered simultaneously, thus, their effects can be assessed at the presence of other interactions. 
As illustrated in Table 1, the relationship between ICT initiatives and public health is contingent on education level $(\beta=0.16, \mathrm{p}<0.01)$ and the direction of interaction pattern for ICT initiatives development and level of public health is consistent with the initial prediction. Thus, H1 is supported. The relationship between ICT initiatives and level of public health is contingent on institutions $(\beta=0.15, \mathrm{p}<0.01)$ and the direction of interaction pattern for ICT initiatives and public health is consistent with our prediction. Hence, we can conclude that $\mathrm{H} 3$ is supported. The relationship between ICT initiatives and public health is not contingent on macroeconomic stability $(\beta=0.05$, n.s.) indicating that $\mathrm{H} 2$ is not supported.

\begin{tabular}{|c|c|c|}
\hline \multicolumn{3}{|c|}{ Table 1. Results } \\
\hline \multirow[b]{2}{*}{ Factors } & \multicolumn{2}{|c|}{ Dependent Indicator (public-health) } \\
\hline & Stage 1 & Stage 2 \\
\hline Physicians density & $-0.17 * *$ & $-0.13 * *$ \\
\hline Nurses density & $0.13 * *$ & 0.03 \\
\hline Hospital beds & $0.11 * *$ & $0.08 *$ \\
\hline ICT & $-.55 * * *$ & $-0.62 * * *$ \\
\hline Education & $-0.35 * * *$ & -0.17 \\
\hline Macro-Economic Stability & 0.03 & 0.05 \\
\hline Institutions & -0.03 & $-0.15 * *$ \\
\hline ICT* Education & & $0.16^{* *}$ \\
\hline ICT* Macro-Economic Stability & & 0.05 \\
\hline ICT $^{*}$ Institutions & & $0.15^{* *}$ \\
\hline $\mathrm{R} 2$ & 0.76 & 0.81 \\
\hline \multicolumn{3}{|c|}{$\begin{array}{l}\text { The table reports the path coefficients } \\
\mathrm{N}=157 ; * \mathrm{p}<0.05 ; \quad * * \mathrm{p}<0.01 ; \quad * * * \mathrm{p}<0.001 \\
\text { Note: See page } 7 \text { for description of variables }\end{array}$} \\
\hline
\end{tabular}

A subsequent testing for effect sizes of the moderation effect where the effect size is computed as a proportion of variance explained by the determination coefficient $R^{2}$ of full model (with moderators) against the $\mathrm{R}^{2}$ of the main-effect model (without moderators) the effect size of $0.26\left(\mathrm{f}^{2}>0.15\right)$ indicated that there is a moderate mediation effect.

\section{Discussion}

Through this research it was expected to understand and assess the environmental factors affecting the relationship between ICT initiatives and delivery of public health 
outcomes. Through the analysis carried out using country level data, it is identified that education level plays a significant role in improving public health as a result of ICT. Thus, we could depict that better education levels of the public will improve the public health status by adopting, transferring and diffusing ICT initiatives. Therefore, it is important to train and make the public knowledgeable about the benefits of ICT initiatives to achieve expected levels of public health improvements. Furthermore, as hypothesized, the interaction effect of the institutions is significant on the relationship between ICT delivery and public health. That is, the availability of a proper framework to transfer the technology to public and having regulations to ensure the quality of ICT will make public more confident of such systems, leading them to utilize ICT regularly in managing their health.

According to this analysis, there is no profound interaction effect of macroeconomic stability on the relationship between ICT and public health. Macro-economic stability indicates the economic growth of a country. However, the economic growth may not be reflected in the adoption of ICT, accessibility of ICT or affordability of ICT. With economic growth, nations tend to demonstrate high income disparity among the population and a major proportion of the income tends to be divided among a smaller segment of the population. Thus, even though high advanced systems are installed, still there may be groups who are disadvantaged and having no access to the latest ICT technologies to manage their health. Secondly, the nations with low macroeconomic stability may still be influencing ICT initiatives even though their economy is not so stable. These counties may introduce low tax rates for ICT goods and may provide ICT facilities at a low cost or at concessions to public with the aim of reducing the ever increasing healthcare expenditure by adopting ICT initiatives for efficient healthcare management and education (Chan et al. 2009).

\section{Conclusion}

\subsection{Limitations}

The use of archived data obtained from various sources can be considered as a limitation in carrying out this research. However, considering the budgetary and human resource constraints, it is not feasible to collect primary data from more than 150 countries. Since these data are retrieved from reputable organizations such as WHO, WEF, World Bank it can be ensured that these data are collected using stringent measures and statistical methods to ensure their validity and reliability. Moreover, many researchers have used similar data for their studies (Mithas et al. 2009; Raghupathi and Wu 2011; Srivastava and Teo 2007)

In this study, we have used 4 independent variables including the moderators. Therefore, the sample size of 40 is adequate to capture fairly small $\mathrm{R}^{2}$ values at a significant level of 0.05 (Hair Jr 2006). Despite these limitations, the findings are useful in assessing the moderating effect of environment factors on the relationship of ICT factors and delivery of public health outcomes. 


\subsection{Implications and Future Research}

As the theoretical implication of this study, we can identify; (1) Contribution made to theoretical discourse of RBV's resource complementary perspective. In previous studies, it is considered that ICT initiatives have direct effect on public health outcomes. However, our study maintains that having a specific resource can improve the outcome rather than having the predictors only (ICT). (2) Contribution made to the knowledge base of IT-healthcare standard in assessing the influence of environmental factors in national level on the relationship between ICT and delivery of public health. That is for better adoption, diffusion and transfer of ICT innovations to improve the level of public health in a nation, it is important to focus on the 3 environment variables we considered.

Capability of this study in assisting practitioners, policy makers and administrators to understand the reasons for various levels of health outcomes and usefulness of these findings in development of policy and in management of complementary assets can be considered as the practical implication of this study.

The findings of our research have implications for future research. First, while we show that macro-economic stability, education and institutions have interaction effect on ICT factors and public health delivery, new complementary assets like technological readiness, culture and gender equality too could be introduced into the model. Second, panel dataset could be used to examine the effect of leads and lags between predictors, moderators and dependent variables.

In conclusion, this study provides a new perspective to the relationship between ICT factors and delivery of public health outcomes by introducing complementary assets, namely, macro-economic stability, education and institutions. Through this study, we found the moderating effect of environmental factors on the relationship between ICT factors and public health outcomes. This will be helpful to understand how ICT should be managed and to understand how ICT initiatives influence the delivery of public health outcomes with reference to complementary assets.

\section{References}

Aanensen, D.M., Huntley, D.M., Feil, E.J., Spratt, B.G.: Epicollect: Linking Smartphones to Web Applications for Epidemiology, Ecology and Community Data Collection. PloS One 4(9), e6968 (2009)

Ackerson, L.K., Viswanath, K.: The Social Context of Interpersonal Communication and Health. Journal of Health Communication 14(S1), 5-17 (2009)

Ahangama, S., Lim, Y.S., Koh, S.Y., Poo, D.C.C.: Revolutionizing Mobile Healthcare Monitoring Technology: Analysis of Features through Task Model. In: International Conference on Human-Computer Interaction, Crete, Greece (2014)

Ahangama, S., Poo, D.C.C.: Moderating Effect of Environmental Factors on Ehealth Development and Health Outcomes: A Country-Level Analysis. In: Bhattacherjee, A., Fitzgerald, B. (eds.) Shaping the Future of ICT Research. IFIP AICT, vol. 389, pp. 143-159. Springer, Heidelberg (2012)

Bagchi, K., Udo, G., Kesh, M.: An Empirical Study Identifying the Factors That Impact Ehealth Infastructure and Ehealth Use (2005) 
Barney, J., Wright, M., Ketchen, D.J.: The Resource-Based View of the Firm: Ten Years after 1991. Journal of Management 27(6), 625-641 (2001)

Braa, J., Hanseth, O., Heywood, A., Mohammed, W., Shaw, V.: Developing Health Information Systems in Developing Countries: The Flexible Standards Strategy. MIS Quarterly, 381-402 (2007)

Byrne, E., Sahay, S.: Participatory Design for Social Development: A South African Case Study on Community. Based Health Information Systems, Information Technology for Development 13(1), 71-94 (2007)

Chan, M., Campo, E., Estève, D., Fourniols, J.-Y.: Smart Homes-Current Features and Future Perspectives. Maturitas 64(2), 90-97 (2009)

Chin, W.W., Marcolin, B.L., Newsted, P.R.: A Partial Least Squares Latent Variable Modeling Approach for Measuring Interaction Effects: Results from a Monte Carlo Simulation Study and an Electronic-Mail Emotion/Adoption Study. Information Systems Research 14(2), 189-217 (2003)

Cole-Lewis, H., Kershaw, T.: Text Messaging as a Tool for Behavior Change in Disease Prevention and Management. Epidemiologic Reviews 32(1), 56-69 (2010)

Connell, N., Young, T.: Evaluating Healthcare Information Systems through an "Enterprise" Perspective. Information \& Management 44(4), 433-440 (2007)

Fjeldsoe, B.S., Marshall, A.L., Miller, Y.D.: Behavior Change Interventions Delivered by Mobile Telephone Short-Message Service. American Journal of Preventive Medicine 36(2), 165-173 (2009)

Goodhue, D., Lewis, W., Thompson, R.: Research Note-Statistical Power in Analyzing Interaction Effects: Questioning the Advantage of Pls with Product Indicators. Information Systems Research 18(2), 211-227 (2007)

Hair Jr, J.F., Black, W.C., Babin, B.J., Anderson, R.E., Tatham, R.L.: Multivariate data analysis (2006)

Heilman, J.M., Kemmann, E., Bonert, M., Chatterjee, A., Ragar, B., Beards, G.M., Iberri, D.J., Harvey, M., Thomas, B., Stomp, W.: Wikipedia: A Key Tool for Global Public Health Promotion. Journal of Medical Internet Research 13(1) (2011)

Henseler, J., Fassott, G.: Testing Moderating Effects in Pls Path Models: An Illustration of Available Procedures. In: Handbook of Partial Least Squares, pp. 713-735. Springer (2010)

Jennett, P., Scott, R., Affleck Hall, L., Hailey, D., Ohinmaa, A., Anderson, C., Thomas, R., Young, B., Lorenzetti, D.: Policy Implications Associated with the Socioeconomic and Health System Impact of Telehealth: A Case Study from Canada. Telemedicine Journal and e-Health 10(1), 77-83 (2004)

Jha, A.K., DesRoches, C.M., Campbell, E.G., Donelan, K., Rao, S.R., Ferris, T.G., Shields, A., Rosenbaum, S., Blumenthal, D.: Use of Electronic Health Records in Us Hospitals. New England Journal of Medicine 360(16), 1628-1638 (2009)

Jones, S., Fox, S.: Generations Online in 2009. Pew Internet and American Life Project, Washington, Dc (2009)

Kauffman, R.J., Kumar, A.: Impact of Information and Communication Technologies on Country Development: Accounting for Area Interrelationships. International Journal of Electronic Commerce 13(1), 11-58 (2008)

Keil, M., Tan, B.C., Wei, K.-K., Saarinen, T., Tuunainen, V., Wassenaar, A.: A Cross-Cultural Study on Escalation of Commitment Behavior in Software Projects. MIS Quarterly, 299-325 (2000) 
Khoumbati, K., Themistocleous, M., Irani, Z.: Evaluating the Adoption of Enterprise Application Integration in Health-Care Organizations. Journal of Management Information Systems 22(4), 69-108 (2006)

Kiecolt, K.J., Nathan, L.E.: Secondary Analysis of Survey Data. Sage Publications, Inc. (1985)

Krishnan, S., Teo, T.: Moderating Effects of Environmental Factors on E-Government, E-Business, and Environmental Sustainability (2011)

Mithas, S., Khuntia, J., Agarwal, R.: Information Technology and Life Expectancy: A CountryLevel Analysis (2009)

Ngwenyama, O., Andoh-Baidoo, F.K., Bollou, F., Morawczynski, O.: Is There a Relationship between Ict, Health, Education and Development? An Empirical Analysis of Five West African Countries from 1997-2003. The Electronic Journal of Information Systems in Developing Countries 23 (2006)

OECD, Better Life Index (2013), http: / / www. oecdbetterlifeindex.org/topics/health/

Porter, M.E., Schwab, K.: The Global Competitiveness Report 2008-2009 (2009)

Raghupathi, W., Wu, S.J.: The Relationship between Information and Communication Technologies and the Delivery of Public Health: A Country Level Study. Communications of the Association for Information Systems 28(1), 99-116 (2011)

Ravichandran, T., Lertwongsatien, C.: Effect of Information Systems Resources and Capabilities on Firm Performance: A Resource-Based Perspective. Journal of Management Information Systems 21(4), 237-276 (2005)

Robine, J.-M., Romieu, I., Cambois, E.: Health Expectancy Indicators. Bulletin-World Health Organization (77), 181-185 (1999)

Shaw, B.: Innovation and New Product Development in the Uk Medical Equipment Industry. International Journal of Technology Management 15(3), 433-445 (1998)

Srivastava, S.C., Teo, T.S.H.: What Facilitates E-Government Development? A Cross-Country Analysis. Electronic Government, An International Journal 4(4), 365-378 (2007)

Teece, D.J.: Profiting from Technological Innovation: Implications for Integration, Collaboration, Licensing and Public Policy. Research Policy 15(6), 285-305 (1986)

Teece, D.J.: The Strategic Management of. In: The Oxford Handbook of Strategy, p. 138 (2006)

Tomasi, E., Facchini, L.A., Maia, M.d.F.S.: Health Information Technology in Primary Health Care in Developing Countries: A Literature Review. Bulletin of the World Health Organization 82(11), 867-874 (2004)

World Bank, World Development Report 1993: Investing in Health,The International Bank of Reconstruction and Development/The World Bank (1993)

World Health Organization, World Health Statistics. WHO Press, Geneva (2011)

Woszczynski, A.B., Whitman, M.E.: The Problem of Common Method Variance in Is Research. In: The Handbook of Information Systems Research, pp. 66-77 (2004)

Wu, S., Chaudhry, B., Wang, J., Maglione, M., Mojica, W., Roth, E., Morton, S.C., Shekelle, P.G.: Systematic Review: Impact of Health Information Technology on Quality, Efficiency, and Costs of Medical Care. Annals of Internal Medicine 144(10), 742-752 (2006)

Wu, S.J., Raghupathi, W.: A Panel Analysis of the Strategic Association between Information and Communication Technology and Public Health Delivery. Journal of Medical Internet Research 14(5) (2012) 